\title{
Prevalence and capsular type distribution of Streptococcus agalactiae isolated from pregnant women in Namibia and South Africa
}

Munyaradzi Mukesi ${ }^{1,2,3^{*}}$, Benson C. Iweriebor ${ }^{1,2}$, Larry C. Obi ${ }^{4}$, Uchechukwu U. Nwodo ${ }^{1,2}$, Sylvester R. Moyo ${ }^{3}$ and Anthony I. Okoh ${ }^{1,2}$

\begin{abstract}
Background: Streptococcus agalactiae or Group B Streptococcus (GBS) is the leading cause of neonatal morbidity and mortality resulting in septicaemia, bacteraemia and meningitis. Long term problems in children range from loss of hearing to mental retardation. While Intrapartum Antibiotic Prophylaxis (IAP) has reduced the incidence of $S$. agalactiae infection, it still remains the leading cause of disease in neonates. GBS has ten capsular types whose distribution varies across the world. Therefore, this study sought to determine the prevalence of GBS in Namibia and South Africa amongst pregnant women between 35 and 37 weeks gestation and elucidate the capsular types.
\end{abstract}

Methods: Lower vaginal and rectal swabs were collected from pregnant women between 35 and 37 weeks gestation. Five hundred and thirty pregnant women were recruited into the study in Windhoek, Namibia while one hundred pregnant women were recruited in the Eastern Cape, South Africa. The swabs were cultured on 5\% sheep blood agar (Biomerieux, New Jersey, USA) for isolation of GBS. Presumptive isolates were confirmed using both the Vitek (2) and molecular techniques targeting the $s c p B$ gene. Capsular typing was performed in a multiplex PCR with capsular specific primer pairs.

Results: The prevalence of GBS in Namibia was 13.6 and 37\% in South Africa respectively. In both countries most women were dually colonised with GBS. Capsular types II, III and V were the most prevalent.

Conclusions: The prevalence of GBS in Namibia was lower than in South Africa in this study. The prevalence in both countries was not different from those reported in other African countries and around the world. The predominant capsular types in this study are the ones commonly associated with adverse maternal outcomes.

Keywords: Prevalence, Capsular type, Streptococcus agalactiae, Pregnant, Women

\section{Background}

Streptococcus agalactiae also known as Group B Streptococcus (GBS) is a gram positive bacteria which is the sole organism in Lancefield group B. The organism was first described in 1887 as a cause of bovine mastitis but was only noted as a human pathogen in 1935 [1] and it has

\footnotetext{
* Correspondence: mukesi@yahoo.co.uk

'SAMRC Microbial Water Quality Monitoring Centre, University of Fort Hare, Private Bag X1314, Alice, Eastern Cape Province 5700, South Africa

${ }^{2}$ Applied and Environmental Microbiology Research Group (AEMREG),

Department of Biochemistry and Microbiology, University of Fort Hare,

Private Bag X1314, Alice, Eastern Cape Province 5700, South Africa

Full list of author information is available at the end of the article
}

been isolated from many other animals including fish, dogs, horses and guinea pigs [2].

GBS primarily colonizes both the gastrointestinal and genital tracts but can also be found in the oropharynx. In the 1970s, GBS emerged as the leading cause of neonatal sepsis and meningitis with case fatality rates of up to $50 \%$ and since then, it has remained the leading cause of neonatal sepsis and meningitis in the United States [3]. The pathogenesis of these infections is based on GBS colonization of the mother vaginally or rectally and on transmission of the organism during labour or delivery [4]. Colonization rates vary between countries but as 
many as $20-40 \%$ of healthy women are asymptomatically colonized and are at risk of transmitting it to their new-born babies [5]. It can cause serious disease in neonates, pregnant women and immune-compromised patients. In pregnant women the disease presents as infection of the genital tract, placenta, amniotic sac or simply bacteraemia. While infection does not cause death in pregnant women, in $10-60 \%$ of the cases it results in either miscarriage or stillbirth in developing countries when compared to with $7-11 \%$ in developed countries [6, 7].

Vertical transmission of GBS from colonized mothers to their new-borns can result in early onset GBS infection which occurs in the first 7 days of life and is a leading cause of invasive bacterial infection in neonates. Mortality in early onset disease is estimated at $5 \%$ and is characterized by bacteraemia, pneumonia and meningitis $[8,9]$. Mortality is higher in preterm infants with case fatality rates of up to $20 \%$ and as much as $30 \%$ in those born before 33 weeks of gestation [5]. Late onset disease refers to infections from one week to 90 days of age and this is attributed primarily to transmission after birth from the mother or other external sources to the neonate. Late onset disease presents primarily with meningitis and associated sequelae such as deafness and developmental disabilities [10].

Surface associated polysaccharides (capsules) are common in both gram positive and gram negative bacteria. Microorganisms develop capsules for protection against environmental factors and survival against the host's defence mechanisms. In human beings, it allows the microorganisms to escape phagocytosis, complement mediated killing and acquired immune responses by masking bacterial antigenic determinants, mimicking host antigens and interfering with complement mediated killing. However, the capsule can also act as a target for specific antibodies, conferring the host with immunity to GBS infection [1].

Capsular serotyping has been one of the mainstays in the descriptive epidemiology of GBS as currently ten capsular serotypes (1a, 1b, 11-IX) have been described based on the antigenicity of their capsular polysaccharides. These capsules represent one of the major virulence factors of GBS and of these, serotype III has been noted to be responsible for the majority of GBS infections including meningitis in neonates [11]. Recent epidemiological studies have pointed out to greater involvement of serotype $\mathrm{V}$, now accounting for GBS disease in approximately $30 \%$ of non-pregnant adults and 14 to $23 \%$ of pregnant women and neonates [12]. Other studies have reported GBS serotypes Ia, Ib, II, III and V as being responsible for most early onset disease [13, 14]. Association of serotypes with disease might have to do with sialic acid residues incorporated in the capsular polysaccharide primary structure.
Capsular polysaccharides are composed of repeating units of four to seven monosaccharides with a backbone and side chains [15]. Of the ten serotypes, eight are closely related genetically and structurally with serotype VIII being distantly related. This suggests that despite the evolutionary pressures toward antigenic variation exerted by hosts' acquired immune responses, GBS capsular polysaccharides still remain highly conserved.

Capsular polysaccharide distribution varies even within geographical areas. In South Africa in 2011, serotype III was found to be common among mothers (37.3\%) and new-borns (36.2\%). Serotypes Ia, Ib and III were more prevalent among pregnant women $(74.1 \%)$ and new-borns (69.6\%) with serotypes III and Ia causing $53.9 \%$ of invasive disease in infants aged 7 to 90 days as compared to Ib, II, IV and V $(<6 \%)$ [16]. A study carried out on pregnant women in Zimbabwe in 2000 reported serotypes III and V as the most common [17] and in a recent study on pregnant women in Zimbabwe, Mavenyengwa et al detected serotypes Ia, Ib, II, III and V [18].

Studies in Malawi [19], Finland [20], Sweden [21], England [22], United States [23], Zimbabwe [18], Gambia [24], Egypt [25] and in Brazil [26] have shown variations in serotype distribution around the world. This study therefore sought to determine the prevalence of GBS and capsular type distribution of isolates colonising pregnant women in Namibia and South Africa.

\section{Methods}

\section{Sample collection, culture and identification of GBS}

Pregnant women between 35 and 37 weeks gestation were recruited into the study on a voluntary basis. Participants targeted were those attending Windhoek Central Hospital maternity clinic, Windhoek (Namibia) (which is urban) while in the Eastern Cape, samples were collected from Mduntsane, Dimbazi and Middle Drift clinics (which is a rural setting). Pregnant women on antibiotic treatment or who had been on treatment seven days prior to recruitment in the study were excluded. In Windhoek, out 610 women approached 530 (86.9\%) took part while in South Africa the recruitment rate was $100 \%$. A low vaginal swab (LVS) and rectal swab (RS) were collected from each consecutive participant who consented to participate. Samples were placed in Amies transport medium (Rochelle chemicals, South Africa), bar-coded for identification, placed in a cooler box containing ice packs and transported to the laboratory. In Namibia, samples were transported to the Microbiology laboratory, Faculty of Health and Applied Sciences, Namibia University of Science and Technology (NUST) for culture and presumptive identification of GBS while samples collected in South Africa were processed at the Applied and Environmental Microbiology Research Group (AEMREG) laboratory, Department of 
Microbiology and Biochemistry, University of Fort Hare (UFH). In both South Africa and Namibia samples were transported and cultured within $2 \mathrm{~h}$ of collection. Molecular confirmation and characterization was done at AEMREG laboratory.

Samples were inoculated onto Columbia blood agar containing 5\% sheep blood (Biomerieux, New Jersey, USA) and incubated at $37^{\circ} \mathrm{C}$ for $18 \mathrm{~h}$ under $5 \%$ carbon dioxide atmosphere. Sterility of the media was established by incubating a representative of the media for $2-5$ days at $35-37^{\circ} \mathrm{C}$ and plates were checked for no evidence of bacterial growth after incubation. Quality control was performed using the ATCC reference strain BAA-2674. Presumptive isolates were identified as GBS based on: $\beta$-haemolysis on Columbia blood agar containing 5\% sheep blood (Biomerieux, New Jersey, USA), gram positive cocci in chains under the microscope after Gram staining, negative catalase reaction, Lancefield grouping with type B antisera (Becton Dickinson, New jersey, USA) and using the Vitek (Biomareux) version 2. All presumptive isolates were stored in $30 \%$ glycerol stocks at $-80{ }^{\circ} \mathrm{C}$ until further analyses.

\section{Molecular confirmation of GBS strains}

Presumptive isolates in glycerol stocks were resuscitated in Todd Hewitt broth (Biomerieux, New Jersey, USA) for $24 \mathrm{~h}$ at $37^{\circ} \mathrm{C}$ and streaked onto Columbia blood agar containing 5\% sheep blood. GBS isolates were confirmed by molecular techniques using a pair of primers specific for the $s c p$ B gene. A single colony of GBS was picked from Columbia blood agar containing $5 \%$ sheep blood (Biomerieux, New Jersey, USA) and emulsified with 2 $\mathrm{mL}$ of nucleic acid free water in a $2 \mathrm{~mL}$ microcentrifuge tube. The tube was boiled at $100^{\circ} \mathrm{C}$ for $15 \mathrm{~min}$ on a Heating Block and thereafter centrifuged at 10,000 rpm (rpm) for $5 \mathrm{~min}$ and supernatant containing GBS DNA was separated from the pellet and stored at $-80^{\circ} \mathrm{C}$. Twelve microliters of One $\mathrm{Taq}^{\mathrm{R}}$ Master Mix with standard buffer (New England Biolabs, United Kingdom) containing: $20 \mathrm{mM}$ Tris- $\mathrm{HCl}, \quad 1.8 \mathrm{mM} \quad \mathrm{MgCl}_{2}, 22 \mathrm{mM}$ $\mathrm{NH}_{4} \mathrm{Cl}, 22 \mathrm{mM} \mathrm{KCl}, 0.2 \mathrm{mM}$ dNTPs, $5 \%$ glycerol, $0.06 \%$ IGEPAL $^{\mathrm{R}}$ CA-630, $0.05 \%$ Tween $^{\mathrm{R}} 20$ and 25 units $/ \mathrm{mL}$ One Taq DNA polymerase, $6 \mathrm{uL}$ of water of PCR grade, $1 \mathrm{uL}$ of $10 \mathrm{pMol}$ of both forward and reverse primers were mixed with $5 \mu \mathrm{L}$ of DNA template to make up a total reaction volume of $25 \mathrm{uL}$. ScpB primer sequences are presented in Table 1.

The cycling conditions were as follows: an initial denaturation of $94^{\circ} \mathrm{C}$ for $4 \mathrm{~min}$ followed by 35 cycles of denaturation at $93^{\circ} \mathrm{C}$ for $1 \mathrm{~min}$, annealing at $57^{\circ} \mathrm{C}$ for 1 min and extension at $72^{\circ} \mathrm{C}$ for $1 \mathrm{~min}$ and a final elongation step of $72{ }^{\circ} \mathrm{C}$ for $7 \mathrm{~min}$ followed by a hold at $4{ }^{\circ} \mathrm{C}$ as described by Desjardins et al., (2004) [27]. The following ATCC reference strains (and respective capsular
Table 1 Oligonucleotide primers for molecular confirmation of GBS

\begin{tabular}{ll}
\hline Name & scpBF \\
\hline Sequence & ACAACGGAAGGCGCTACTGTTC \\
Name & scpBR \\
Sequence & ACCTGGTGTTGACCTGAACTA
\end{tabular}

(Adopted from Elbaradie et al., 2009) [37]

type) were used as positive controls during capsular typing: BAA-1138 (Ia), BAA-1174 (Ib), BAA-2675 (II), BAA-2674 (III), BAA-2673 (IV), BAA-2672 (V), BAA-2671 (VI), BAA-2670 (VII), BAA-2669 (VIII) and BAA-2668 (IX). Procedure (negative) controls were used during PCR to detect non-specific amplification.

Two microliters of amplicons were loaded on $1 \%$ agarose gel stained with $10 \mu \mathrm{L}$ ethidium bromide and electrophoresed for $45 \mathrm{~min}$ at $110^{\circ} \mathrm{C}$ in a $0.5 \mathrm{X}$ Tris/Borate/EDTA (TBE) buffer. Amplification was verified in a gel documentation system and photographed.

\section{Determination of capsular types of the isolates using multiplex PCR}

Table 2 presents the oligonucleotide primers used for capsular typing. The capsular types were grouped according to annealing temperature as follows:

Types 1a, 1b, II \& III at $58^{\circ} \mathrm{C}$; IV, V, VI \& VII at $59^{\circ} \mathrm{C}$ and VIII at $56^{\circ} \mathrm{C}$.

Twelve microliters of One $\mathrm{Taq}^{\mathrm{R}}$ Master Mix with standard buffer (New England Biolabs, United Kingdom) containing: $20 \mathrm{mM}$ Tris- $\mathrm{HCl}, 1.8 \mathrm{mM} \mathrm{MgCl}_{2}, 22 \mathrm{mM}$ $\mathrm{NH}_{4} \mathrm{Cl}, 22 \mathrm{mM} \mathrm{KCl}, 0.2 \mathrm{mM}$ dNTPs, 5\% glycerol, $0.06 \%$ IGEPAL $^{\mathrm{R}}$ CA-630, $0.05 \%$ Tween $^{\mathrm{R}} 20$ and 25 units $/ \mathrm{mL}$

Table 2 Oligonucleotide primers for capsular typing

\begin{tabular}{|c|c|c|}
\hline Primer name & Sequence & Band size (bp) \\
\hline $\begin{array}{l}\text { la-F } \\
\text { la-R }\end{array}$ & $\begin{array}{l}\text { GGTCAGACTGGATTAATGGTATGC } \\
\text { GTAGAAATAGCCTATATACGTTGAATGC }\end{array}$ & 521 \\
\hline $\begin{array}{l}\mathrm{Ib}-\mathrm{F} \\
\mathrm{Ib}-\mathrm{R}\end{array}$ & $\begin{array}{l}\text { TAAACGAGAATGGAATATCACAAACC } \\
\text { GAATTAACTTCAATCCCTAAACAATATCG }\end{array}$ & 770 \\
\hline $\begin{array}{l}I I-F \\
I I-R\end{array}$ & $\begin{array}{l}\text { GCTTCAGTAAGTATTGTAAGACGATAG } \\
\text { TTCTCTAGGAAATCAAATAATTCTATAGGG }\end{array}$ & 397 \\
\hline $\begin{array}{l}I I I-F \\
I I I-R\end{array}$ & $\begin{array}{l}\text { TCCGTACTACAACAGACTCATCC } \\
\text { AGTAACCGTCCATACATTCTATAAGC }\end{array}$ & 1826 \\
\hline $\begin{array}{l}\text { IV-F } \\
\text { IV-R }\end{array}$ & $\begin{array}{l}\text { GGTGGTAATCCTAAGAGTGAACTGT } \\
\text { CCTCCCCAATTCGTCCATAATGGT }\end{array}$ & 578 \\
\hline $\begin{array}{l}V-F \\
V-R\end{array}$ & $\begin{array}{l}\text { GAGGCCAATCAGTTGCACGTAA } \\
\text { AACCTTCTCCTTCACACTAATCCT }\end{array}$ & 701 \\
\hline $\begin{array}{l}\text { VI-F } \\
V I-R\end{array}$ & $\begin{array}{l}\text { GGACTTGAGATGGCAGAAGGTGAA } \\
\text { CTGTCGGACTATCCTGATGAATCTC }\end{array}$ & 487 \\
\hline $\begin{array}{l}\text { VII-F } \\
\text { VII-R }\end{array}$ & $\begin{array}{l}\text { CCTGGAGAGAACAATGTCCAGAT } \\
\text { GCTGGTCGTGATTTCTACACA }\end{array}$ & 371 \\
\hline $\begin{array}{l}\text { VIII-F } \\
\text { VIII-R }\end{array}$ & $\begin{array}{l}\text { AGGTCAACCACTATATAGCGA } \\
\text { TCTTCAAATTCCGCTGACTT }\end{array}$ & 282 \\
\hline
\end{tabular}

(Adopted from Poyart et al., 2007) [38] 
One Taq DNA polymerase, was mixed with $6 \mu \mathrm{L}$ of nuclease free water, I uL each of $10 \mathrm{pMol}$ of reverse and forward primers for the respective capsular types, $5 \mathrm{uL}$ of DNA template to make a final reaction volume of $25 \mathrm{uL}$.

The cycling conditions were as follows: $94{ }^{\circ} \mathrm{C}$ for 4 min as an initial denaturation followed by 35 cycles of denaturation at $93^{\circ} \mathrm{C}$ for $1 \mathrm{~min}$, annealing at the respective annealing temperature for $1 \mathrm{~min}$ and extension at $72{ }^{\circ} \mathrm{C}$ for $1 \mathrm{~min}$ with a final elongation step of $72{ }^{\circ} \mathrm{C}$ for $7 \mathrm{~min}$ followed by a hold at $4{ }^{\circ} \mathrm{C}$. Amplification was verified in a $1 \%$ agarose gel stained with ethidium bromide and electrophoresed at $120 \mathrm{~V}$ for 45 min in a $0.5 \mathrm{X}$ TBE buffer and thereafter viewed in a transilluminator and photographed.

\section{Results}

Out of the 530 pregnant women recruited in Namibia, $72(13.6 \%)$ were colonized with GBS vaginally, rectally or both while in South Africa, out of 100 women screened, 37 (37\%) were colonized with GBS. All the isolates were confirmed as GBS by molecular techniques. The frequency of distribution of GBS in Namibia and South Africa is shown in Tables 3 and 4 while that of the capsular type in both countries are shown in Tables 5 and 6 respectively.

\section{Discussion}

The prevalence of GBS colonization varies around the world according to different geographical locations as shown in studies on the prevalence of GBS conducted on both non-pregnant and pregnant women $[28,29]$. The prevalence of GBS among pregnant women between 35 and 37 weeks gestation in Windhoek was $13.6 \%$ which is low compared to findings of other Southern African countries like South Africa (30.9\% \& 23\%) in 2015 and 2016 and Zimbabwe (21-47\%) in 2010 [18, 30, 31]. This study was based on an urban population and GBS colonization has been shown to be dependent on factors like sanitation and educational levels of pregnant women.

In South Africa, this current study showed a GBS prevalence of $37 \%$ in the Eastern Cape which is much higher than the prevalence in Windhoek (Namibia) and other South African studies done by Chukwu et al., (2015) and Cools et al., (2016) [30, 31]. Sampling of

Table 3 Frequency distribution of GBS in Namibian isolates according to colonization site

\begin{tabular}{ll}
\hline Colonization site & Frequency (\%) \\
\hline Vagina only & $27(37.5)$ \\
Rectum only & $13(18.1)$ \\
Dual colonization & $32(44.4)$ \\
Total & $72(100)$ \\
\hline
\end{tabular}

Table 4 Frequency distribution of GBS in Namibian isolates according to colonization site

\begin{tabular}{ll}
\hline Colonization site & Frequency (\%) \\
\hline Vagina only & $5(13.5)$ \\
Rectum only & $2(5.4)$ \\
Dual colonization & $30(81.1)$ \\
Total & $37(100)$ \\
\hline
\end{tabular}

different populations could contribute to differences in prevalence rates of GBS colonization as a similar study in Zimbabwe in 2006, reported a prevalence of $60 \%$ in a rural population and $46 \%$ in an urban population [32]. Factors which affect GBS colonization include ethnicity, maternal age, parity, marital status and educational level and these factors vary between rural and urban populations. The Windhoek population was predominantly urban while in the Eastern Cape, Amatole Municipality which is largely rural is ranked among the poorest municipalities in South Africa [33]. In a study conducted by de Steenwinkel et al., (2008) in Mozambique, the reported prevalence of GBS was $1.8 \%$ in one of the poorest communities in Maputo which is much lower than the prevalence from this current study. The low prevalence of GBS was speculated to be linked to cultural norms and personal hygienic habits including male circumcision [34].

The prevalence of GBS in both Namibia and South Africa as shown in this study were not very different from those reported for other African countries such as Tanzania (23\%), Uganda (28.8\%) and Kenya (20.2\%) [12, $29,31]$. The differences in the prevalence rates could be attributed to difference in study designs, prevalence at different gestational ages and different colonization rates in the different geographical regions. The prevalence rates in the different African regions do not show alignment to a particular region as the rates are varied.

Prevalence rates around the world vary between 10 and $40 \%$ [6] as the prevalence rates of GBS in Europe among pregnant women vary between 6.5 and 36\% with more than a third of the studies reporting a prevalence

Table 5 Frequency distribution of capsular types among pregnant women in Namibia

\begin{tabular}{ll}
\hline Capsular type & Frequency (\%) \\
\hline II & $69(60.0)$ \\
III & $29(25.2)$ \\
V & $12(10.4)$ \\
Ia & $3(2.6)$ \\
IV & $2(1.7)$ \\
Ib & $0(0)$ \\
Total & $115(100)$ \\
\hline
\end{tabular}


Table 6 Frequency distribution of capsular types among pregnant women in South Africa

\begin{tabular}{ll}
\hline Capsular type & Frequency (\%) \\
\hline II & $35(52.2)$ \\
V & $12(17.9)$ \\
Ia & $11(16.4)$ \\
IV & $6(9.0)$ \\
Ib & $1(1.5)$ \\
Total & $2(3.0)$ \\
\hline
\end{tabular}

of $20 \%$ or greater. Eastern Europe had a prevalence of 19.7-29.3\%, Western Europe 11-21\%, Scandinavia 24.3$36 \%$ and Southern Europe 6.5-32\% [35] and they are similar to those recorded in African studies. The prevalence rates in both Namibia and South Africa are not very different from those in other parts of the world despite the differences in geographical location.

As shown in Tables 3 and 4, 27 (37.5\%) study participants from Namibian had vaginal colonization and 13 (18.1\%) had rectal colonization while 32 (44.4\%) were simultaneously colonized vaginally and rectally. In the South African study subjects, 5 (13.5\%) were vaginally colonized while $30(81.1 \%)$ were dually colonized with GBS. In both populations, most of the women were dually colonized. In a similar study in Tanzania, colonization rates were $12.3 \%$ in the vagina and $5 \%$ in the rectum [12]. GBS colonises both the vagina and the rectum with colonization of either site resulting in vertical transmission to the baby during labour and or delivery while dual colonization of both the rectum and vagina increases the risk of vertical transmission to the new-born so the Centre for Disease Control (CDC) recommends rectovaginal sampling for detection of GBS.

GBS capsular types vary in different geographical locations. Capsular types Ia, II, III and V are the most prevalent around the world. Capsular type II was most prevalent in this study in both Namibia (59.4\%) and South Africa (52.2\%) as shown in Tables 5 and 6. Capsular types II, III and V constituted $94.1 \%$ of the Namibian isolates and $86.5 \%$ of the South African isolates in this study. These capsular types have been reported to be commonly associated with adverse pregnancy outcomes as well as neonatal morbidity and mortality [22] and they are predominantly the capsular types which have been isolated in other Southern Africa countries such as Zimbabwe and South Africa. However, a report from a study in South Africa in 2015 found a high prevalence of capsular types III (29.7\%), Ia (25.8\%) and V (10.9\%) [30]. In a similar study in South Africa, Cools et al., (2016), reported a high prevalence of the same capsular types Ia (36.8\%), V (26.3\%) and III (14.0\%).) while in Zimbabwe,
Mavenyengwa et al., (2010) reported similar findings with the following prevalences: Ia (15.7\%), Ib (11.6\%), II (8.3\%), III (38.8\%) and V (24.0\%) [18, 31]. Similar studies in Europe have equally reported capsular types II, III and Ia to be the most prevalent [35].

Capsular typing of GBS is important in determining the pathogenicity of the isolates and for epidemiological purposes. The capsular type distribution depends on factors such as geographical region, ethnicity or other characteristics of the population studied. Studies have shown variations in capsular type distribution of $S$. agalactiae when isolated from pregnant and non-pregnant women [36].

Even though the results of this study are similar to those of other African studies and are comparable to European countries, most of the women were dually colonised predominantly by capsular types commonly associated with adverse maternal outcomes and this poses a risk to both the mother and baby. However, the research was not able to follow up the outcomes of both the pregnant mothers and their babies.

\section{Conclusion}

In this study, the prevalence of GBS in Namibia and South Africa was not different from other African countries and countries around the world. However, most of the pregnant women were both vaginally and rectally colonised with GBS which increases the risk of vertical transmission to the babies during delivery. The GBS capsular types predominant in pregnant women were the same capsular types prevalent in other African studies and commonly associated with adverse pregnancy outcomes.

\section{Abbreviations}

AEMREG: Applied and Environmental Microbiology Research Group; CDC: Centre for Disease Control and Prevention; GBS: Group B Streptococcus; GMRDC: Govan Mbeki Research and Development Centre; IAP: Intrapartum Antibiotic Prophylaxis; LVS: Low Vaginal Swab; NUST: Namibia University of Science and Technology; RS: Rectal Swab; UFH: University of Fort Hare; USA: United States of America

\section{Acknowledgements}

The authors would like to express their gratitude to the National Research Foundation of South Africa and the National Commission of Research Science and Technology, Namibia.

\section{Funding}

The authors are grateful to the National Research Fund (NRF), SA and National Commission of Research Science and Technology (NCRST), Namibia for funding the research. These funding bodies only provided financial support and did not influence the research design, implementation or dissemination of its findings.

\section{Availability of data and materials}

The datasets used and/or analysed during the current study are available from the corresponding author on reasonable request.

\section{Authors' contributions}

MM designed, collected data, analysed, interpreted results and prepared the article for publication. $\mathrm{BCl}$ designed, collected data, analysed, interpreted results, supervised and revised article for publication. LCO conceived,

designed the project, supervised, obtained ethical clearance and revised the 
manuscript. UUN conceived, designed, supervised and revised the manuscript. SRM conceived the idea, designed, supervised and revised the manuscript. AlO conceived the idea, designed, supervised and revised the manuscript. All authors read and approved the manuscript.

\section{Ethics approval and consent to participate}

Ethical approval for the research was granted by Govan Mbeki Research and Development Centre (GMRDC), University of Fort Hare (UFH). Ethical clearance was granted by the Ministry of Health and Social Services (Namibia) and the Department of Health, Eastern Cape (South Africa). Written informed consent was obtained from each participant prior to sample collection which was carried out by qualified midwives.

\section{Consent for publication}

Not applicable.

\section{Competing interests}

The authors declare that they have no competing interests.

\section{Publisher's Note}

Springer Nature remains neutral with regard to jurisdictional claims in published maps and institutional affiliations.

\section{Author details \\ 'SAMRC Microbial Water Quality Monitoring Centre, University of Fort Hare, Private Bag X1314, Alice, Eastern Cape Province 5700, South Africa. ${ }^{2}$ Applied and Environmental Microbiology Research Group (AEMREG), Department of Biochemistry and Microbiology, University of Fort Hare, Private Bag X1314, Alice, Eastern Cape Province 5700, South Africa. ${ }^{3}$ Department of Health Sciences, Faculty of Health and Applied Sciences, Namibia University of Science and Technology, Private Bag, Windhoek 13388, Namibia. ${ }^{4}$ Academic and Research Division, University of Fort Hare, Private Bag X1314, Alice, Eastern Cape Province 5700, South Africa.}

\section{Received: 22 March 2018 Accepted: 12 February 2019}

Published online: 20 February 2019

\section{References}

1. Le Doare K, Kampmann B. Breast milk and group B streptococcal infection: Vector of transmission or vehicle for protection? Vaccine. 2014;32:3128-32.

2. Johri AK, Lata $H$, Yadav $P$, Dua M, Yang Y, Xu X, et al. Epidemiology of group B Streptococcus in developing countries. Vaccine. 2013;31(Suppl 4): D43-5. https://doi.org/10.1016/j.vaccine.2013.05.094.

3. Lo CW, Liu HC, Lee CC, Lin CL, Chen CL, Jeng MJ, Chiu CH. Serotype distribution and clinical correlation of Streptococcus agalactiae causing invasive disease in infants and children in Taiwan. J Microbiol Immunol Infect. 2017;S1684-1182(17):30228-1. https://doi.org/10.1016/j. jmii.2017.09.002.

4. Whidbey C, Harrell MI, Burnside K, Ngo L, Becraft AK, lyer LM, et al. A hemolytic pigment of group B Streptococcus allows bacterial penetration of human placenta. J Exp Med. 2013;210(6):1265-81. https://doi.org/10.1084/ jem.20122753.

5. Chen VL, Avci FY, Kasper DLA. Maternal vaccine against group $B$ Streptococcus: past, present and Future. Vaccine. 2013;31(4):D13-9.

6. Dangor Z, Lala SJ, Cutland CL, Koen A, Jose L, Nakwa F, Ramdin T, Fredericks J, Wadula J, Madhi SA. Burden of invasive group B Streptococcus disease and early neurological sequelae in south African infants. PLoS One. 2015;10(4):e0123014. https://doi.org/10.1371/journal.pone.0123014.

7. Vincent P, Davies R, Debashis R. Group B streptococcus tricuspid endocarditis presenting with arthralgia in a postpartum woman: a case report. J Med Case Rep. 2012;6:242. https://doi.org/10.1186/1752-1947-6-242.

8. Nathoo KJ, Pazvakavamba I, Chidede OS, Chirisa C. Neonatal meningitis in Harare, Zimbabwe: a 2-year review. Ann Trop Paediatr. 1991;11(1):11-5.

9. Dauby N, Chamekh M, Melin P, Slogrove AL, Goetghebuer T. Increased risk of group B Streptococcus invasive infection in HIV exposed but uninfected infants: a review of the evidence and possible mechanisms. Front Immunol. 2016;7:505. https://doi.org/10.3389/fimmu.2016.00505.

10. Shabayek S, Abdalla S, Abouzeid AM. Serotype and surface protein gene distribution of colonizing group B streptococcus in women in Egypt. Epidemiol Infect. 2014;142(1):208-10. https://doi.org/10.1017/ S0950268813000848.
11. Karunakaran R, Raja NS, Puthucheary SD. Group B streptococcus infection: epidemiology, serotypes and antimicrobial susceptibility of selected isolates in the population beyond infancy. Jpn J Infect Dis. 2009;62:192-4.

12. Joachim A, Matee MI, Massawe FA, Lyamuya EF. Maternal and neonatal colonisation of group B Streptococcus at Muhumbili National Hospital in Dar Es Salaam, Tanzania, prevalence risk factors and antimicrobial resistance, BMC Public Health 2009; 1(9):437.

13. Joubrel C, Tazi A, Six A, Dmytruk N, Touak G, Bidet P, et al. Group B streptococcus neonatal invasive infections, France 2007-2012. Clin Microbiol Infect. 2015;21(10):910-6. https://doi.org/10.1016/j.cmi.2015.05.039.

14. Lin FY, Clemens JD, Azimi PH, Regan JA, Weisman LE, Philips JB 3rd, et al. Capsular polysaccharide types of group B streptococcal isolates from neonates with early-onset systemic infection. J Infect Dis. 1998;177(3):790-2.

15. Francesco B, Edmondo C, Chiara T, Laura M, Stefano C, Roberto R, et al. Structure of the type IX group B Streptococcus capsular polysaccharide and its evolutionary relationship with types V and VII. J Biol Chem. 2014;289(34): 23437-48. https://doi.org/10.1074/jbc.M114.567974.

16. Madzivhandila M, Adrian PV, Cutland CL, Kuwanda L, Schrag SJ, Madhi SA. Serotype distribution and invasive potential of group B streptococcus isolates causing disease in infants and colonizing maternal new-born dyads. PLoS One. 2011;6(3):e17861. https://doi.org/10.1371/journal.pone.0017861.

17. Moyo SR, Mudzori J, Tswana SA, Maeland JA. Prevalence, capsular type distribution, anthropometric and obstetric factors of group B Streptococcus (Streptococcus agalactiae) colonization in pregnancy. Cent Afr J Med. 2000; 46(5):115-20.

18. Mavenyengwa RT, Afset JE, Schei B, Berg S, Caspersen T, Bergseng H, Moyo SR. Group B Streptococcus colonization during pregnancy and maternalfetal transmission in Zimbabwe. Acta Obstet Gynecol Scand. 2010;89(2):2505. https://doi.org/10.3109/00016340903398029.

19. Gray KJ, Bennett SL, French N, Phiri AJ, Graham SM. Invasive group B streptococcal infection in infants Malawi. Emerg Infect Dis. 2007;13(2):223-9.

20. Kalliola S, Vuopio-Varkila J, Takala AK, Eskola J. Neonatal group B streptococcal disease in Finland: a ten-year nationwide study. Pediatr Infect Dis J. 1999;18(9):806-10.

21. Gudjónsdóttir MJ, Hentz E, Berg S, Backhaus E, Elfvin A, Kawash S, Trollfors B. Serotypes of group B streptococci in western Sweden and comparison with serotypes in two previous studies starting from 1988. BMC Infect Dis. 2015; 15:507. https://doi.org/10.1186/s12879-015-1266-4.

22. Lamagni TL, Keshishian C, Efstratiou A, Guy R, Henderson KL, Broughton K, Sheridan $E$. Emerging trends in the epidemiology of invasive group $B$ streptococcal disease in England and Wales, 1991-2010. Clin Infect Dis. 2013; 57(5):682-8. https://doi.org/10.1093/cid/cit337.

23. Teatero S, Ferrieri P, Martin I, Demczuk W, McGeer A, Fittipaldi N. Serotype distribution, population structure and antimicrobial resistance of group B Streptococcus strains recovered from colonized pregnant women. J Clin Microbiol. 2016;55(2):412-22. https://doi.org/10.1128/JCM.01615-16.

24. Le Doare K, Jarju S, Darboe S, Warburton F, Gorringe A, Heath PT, Kampmann B. Risk factors for group B Streptococcus colonisation and disease in Gambian women and their infants. J Inf Secur. 2016;72(3):283-94. https://doi.org/10.1016/j.jinf.2015.12.014

25. Shabayek SA, Abdalla S, AMH A. Vaginal Carriage and Antibiotic susceptibility profile of group B Streptococcus during late pregnancy in Ismailia, Egypt. J Infect Public Health. 2009;2(2):86-90.

26. Barbosa NG, Dos Reis H, Mantese OC, Mussi-Pinhata MM, Abdallah VO, Gontijo Filho PP. Early-onset neonatal sepsis by group B Streptococcus in a Brazilian public hospital. Braz J Infect Dis. 2016;20(6):647-8. https://doi.org/ 10.1016/j.bjid.2016.07.013.

27. Desjardins M, Delgaty KL, Ramotar K, Seetaram C, Toye B. Prevalence and mechanisms of erythromycin resistance in group a and group $B$ Streptococcus: implications for reporting susceptibility results. J Clin Microbiol. 2004;42(12):5620-3. https://doi.org/10.1128/JCM.42.12.5620-5623.2004.

28. Alp F, Findik D, Dagi H, Arslan U, Pekin A, Yilmaz S. Screening and genotyping of group B Streptococcus in pregnant and non-pregnant women in Turkey. J Infect Dev Ctries. 2016;10(3):222-6. https://doi.org/10. 3855/jidc.6190.

29. Namugongo A, Bazira J, Fajardot Y, Joseph N. Group B Streptococcus colonisation among pregnant women attending antenatal care at tertiary hospital in rural South Western Uganda. Int J Microbiol. 2016. https://doi. org/10.1155/2016/3816184.

30. Chukwu MO, Mavenyengwa RT, Monyama CM, Bolukaoto JY, Lebelo SL, Maloba MRB, et al. Antigenic distribution of Streptococcus agalactiae isolates 
from pregnant women at Garankuwa hospital South Africa. Germs. 2015; 5(4):125-33.

31. Cools P, Jespers V, Hardy L, Crucitti T, Delany-Moretlwe S, Mwaura M, et al. A multi country cross sectional study of vaginal carriage of group $B$

Streptococcus and Escherichia coli in resource poor settings: Prevalence and risk factors. PLoS. 2016;11(1):e0148052.

32. Mavenyengwa RT, Masunga P, Meque E, Kudinha T, Moyo SR, Bevanger $L$, et al. Streptococcus agalactiae (group B streptococcus (GBS)) colonisation and persistence, in pregnancy; a comparison of two diverse communities (rural and urban). Cent Afr J Med. 2006;52(3-4):38-43.

33. Baiyegunhi LSS, Fraser GCG. Poverty incidence among smallholder farmers in the Amathole District municipality, eastern Cape Province South Africa. J Hum Ecol. 2014;46(3):261-73.

34. de Steenwinkel FD, Tak HV, Muller AE, Nouwen JL, Oostvogel PM, Mocumbi SM. Low carriage rate of group B Streptococcus in pregnant women in Maputo Mozambique. Trop Med Int Health. 2008;13(3):427-9.

35. Barcaite E, Bartusevicius A, Tameliene R, Kliucinskas M, Maleckiene L, Nadisauskiene R. Prevalence of maternal group B Streptococcus colonisation in European countries. Acta Obstet Gynaecol Scand. 2008;87(3):260-71. https://doi.org/10.1080/00016340801908759.

36. Wang P, Ma Z, Tong J, Zhao R, Shi W, Yu S, et al. Serotype distribution, antimicrobial resistance, and molecular characterization of invasive group B Streptococcus isolates recovered from Chinese neonates. Int J Infect Dis. 2015;37:115-8. https://doi.org/10.1016/j.ijid.2015.06.019.

37. Elbaradie SMY, Mahmoud M, Farid M. Maternal and neonatal screening for group B streptococci by SCP B gene based PCR: a preliminary study. Indian J Med Microbiol. 2009;27(1):17-21.

38. Poyart C, Tazi A, Réglier-Poupet H, Billoët A, Tavares N, Raymond J, TrieuCuot P. Multiplex PCR assay for rapid and accurate capsular typing of group B streptococci. J Clin Microbiol. 2007;45(6):1985-8. https://doi.org/10.1128/ JCM.00159-07.

Ready to submit your research? Choose BMC and benefit from:

- fast, convenient online submission

- thorough peer review by experienced researchers in your field

- rapid publication on acceptance

- support for research data, including large and complex data types

- gold Open Access which fosters wider collaboration and increased citations

- maximum visibility for your research: over $100 \mathrm{M}$ website views per year

At $\mathrm{BMC}$, research is always in progress.

Learn more biomedcentral.com/submissions 